\title{
Embracing the Complexity of Primary Health Care: System-Based Tools and Strategies for Researching the Case Management Process
}

\author{
Kim D Graham (1D) \\ Amie Steel ${ }^{1}$ \\ Jon Wardle ${ }^{2}$
}

'Australian Research Centre in Complementary and Integrative Medicine, Faculty of Health, University of Technology, Sydney, NSW, 2007, Australia; ${ }^{2}$ National Centre for Naturopathic Medicine, Southern Cross University, Lismore, NSW, 2480,

Australia

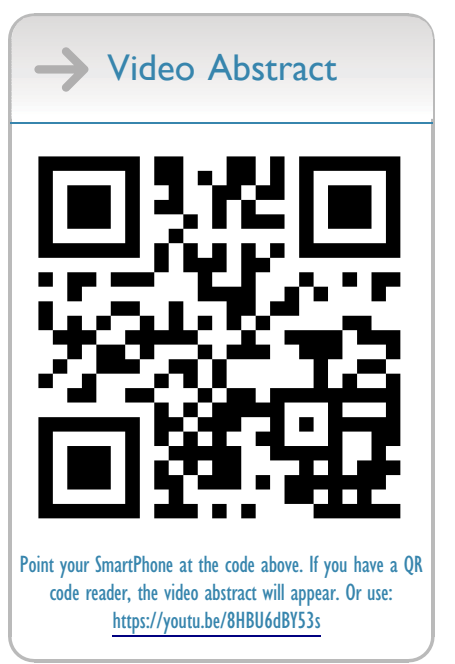

Correspondence: Kim D Graham Email kim.d.graham@student.uts.edu.au

\begin{abstract}
The provision of health care is frequently a complex process, and favourable clinical outcomes are dependent on the effective management of this complexity. Contemporary medicine and health care practices that are biomedically aligned have been informed by a reductionist paradigm, potentially creating a misalignment between health care and the human organism as a complex adaptive system. Complexity science is increasingly gaining momentum within the academic literature and is being employed across a wide range of scientific disciplines, although this is less evident in medicine. Limited evidence was found within the literature of a complexity science framework being used to explore and inform individual health care practices; in this paper, this gap will be explored through consideration of the use of strategies and tools (specifically mind maps, computer-generated network mappings, exploratory data analysis, and computer-derived network analysis) which are congruent with a complexity science framework. This information may be useful to researchers investigating health care provision and to clinicians wishing to incorporate a complexity sensibility within their practice.
\end{abstract}

Keywords: complexity science, health care, mind map, network mapping, case management, complex adaptive systems

\section{The Complexity of Health Care}

Health care provision within a clinical setting is often a complex and intricate task, and especially so when managing chronic illness, comorbidities, and polypharmacy. This complexity extends beyond the interactions between the various systems and organs of the material body and encompasses an extensive range of influences, such as the body-mind link and the lived environment. For example, psychoneuroimmunology research increasingly demonstrates the effect of the mind on physical health; ${ }^{1-3}$ placebo research shows how expectations, conditioning, and context influence treatment outcomes; ${ }^{4-6}$ the link between wellbeing, diet and lifestyle has long been recognised; ${ }^{7,8}$ and research has established an association between positive social connection and health and longevity. ${ }^{9-11}$ To be better understood and further developed, this complexity lends itself to a paradigm that is nonlinear and systems-based rather than reductionistic in its framing. In this paper, we identify potential methods for exploring human health using a systems-based approach, which may support the ongoing evolution of clinical health care to better reflect its complex nature and advance its quality and safety. 


\section{The Emergence of Complexity Science}

Since the early-twentieth century, systems thinking and complexity science has had a growing presence in research and academia. ${ }^{12,13}$ Since the early-twenty-first century, this perspective has increasingly been developed and implemented across a wide range of academic disciplines including artificial intelligence, information technology, business, the social sciences, ecology, biology, and the computer sciences, ${ }^{14}$ and has become a prime focus in the natural and social sciences. ${ }^{15}$ Advancements in computer technology have occurred in parallel to these theoretical developments with a resulting increase in the capacity for large-scale network modelling and manipulation, allowing for the mapping and evaluation of complex systems. ${ }^{14}$ While these applications have not been health care focused, the human body as a complex system lends itself to a similar framework.

Complexity science reveals how a multitude of interacting elements function within an ever-changing context and give rise to adaptive responses emerging as a result of the interactions collectively within any system and between any system and its environment. ${ }^{12,16} \mathrm{~A}$ "system" is defined as something being whole within itself and composed of parts that are interacting for a shared purpose. ${ }^{12}$ "Complex systems" are systems whose interacting parts give rise to distinct properties, such as emergence, nonlinearity, adaptation, feedback loops, and spontaneous order; complex systems lack central control and exhibit sensitivity to starting conditions and small perturbations; ${ }^{17}$ examples include economies, the nervous system, the climate, human organisms, and business and health care organisations. Linear systems rarely occur in nature; instead, it is nonlinear systems that are pervasive. ${ }^{18} \mathrm{At}$ the system level, nonlinear effects lead to emergent outcomes and global patterns that provide insights into complex situations. ${ }^{15}$ However, these insights depend upon a shift from a reductionistic and mechanistic perspective to one of probabilities and propensities, ${ }^{15}$ from ordered and linear, to holistic and pattern-based. Accordingly, disease manifestation may be considered as a non-linear continuum of pattern deviations away from a healthy state. ${ }^{19}$

\section{Complex Adaptive Systems and Human Health}

Complex adaptive systems (CAS) are a ubiquitous nonlinear and dynamic form of complex system ${ }^{15}$ defined by their ability to adapt to a changing environment; these are systems that can learn and have the potential to exhibit novel evolving structure and properties. ${ }^{20}$ Human organisms are an example of a CAS (see Figure 1). CAS have various identifying characteristics, which also exemplify the human organism, such as being a whole self-sustaining system functioning within an environment of multiple nested systems, which is dynamic, evolving, and characterised by emergence, interactive causation, and elaborate interconnectedness. ${ }^{16}$ Further, CAS exhibit unpredictable, exponential, and synergistic emergence of coherent global order, which arises as a result of the operation of the whole system and not through the activity and properties of individual components. ${ }^{16}$ This emergence is driven by self organisation, creating an integrated system responding as an integrated whole, and generating system resilience and adaptability. ${ }^{16} \mathrm{CAS}$, such as human organisms, are paradoxically stable while continuously adapting and evolving; ${ }^{21}$ balance is achieved through constant fluctuation and dynamic change. ${ }^{15}$

\section{Biomedicine and Complexity}

Despite the human organism being by nature a CAS, biomedicine operates according to a philosophical framework, which does not fully embrace this. Biomedically cognisant health care engages with the human organism as though it is other than a CAS because it is primarily informed by a reductionist paradigm. Biomedicine arose during the historical time of industrialisation and increasing mechanical prowess, and biomedical philosophy was correspondingly influenced so that the human organism was viewed as a complicated machine reliant on deterministic principles. ${ }^{21,22}$ When viewed through a reductionistic and mechanistic prism, all natural systems are characterised as being comprised of simple indivisible elements, ${ }^{21}$ encouraging notions of linear causality. ${ }^{23}$ These indivisible elements are considered to be the key to deducing and explaining high-level function and, as a result, the best and most logical manner to investigate a system is considered to be at the lowest level possible. ${ }^{21,24}$ However, essential to this reductionist approach is the condition that a linear system is being explored, ${ }^{24}$ a flawed assumption when considering the health of a CAS, such as the human organism.

\section{Application of Complexity Science to Health and Health Care}

Despite widespread application across a range of scientific disciplines, complexity thinking has been less methodically implemented within health care. ${ }^{13,24,25}$ To date, 


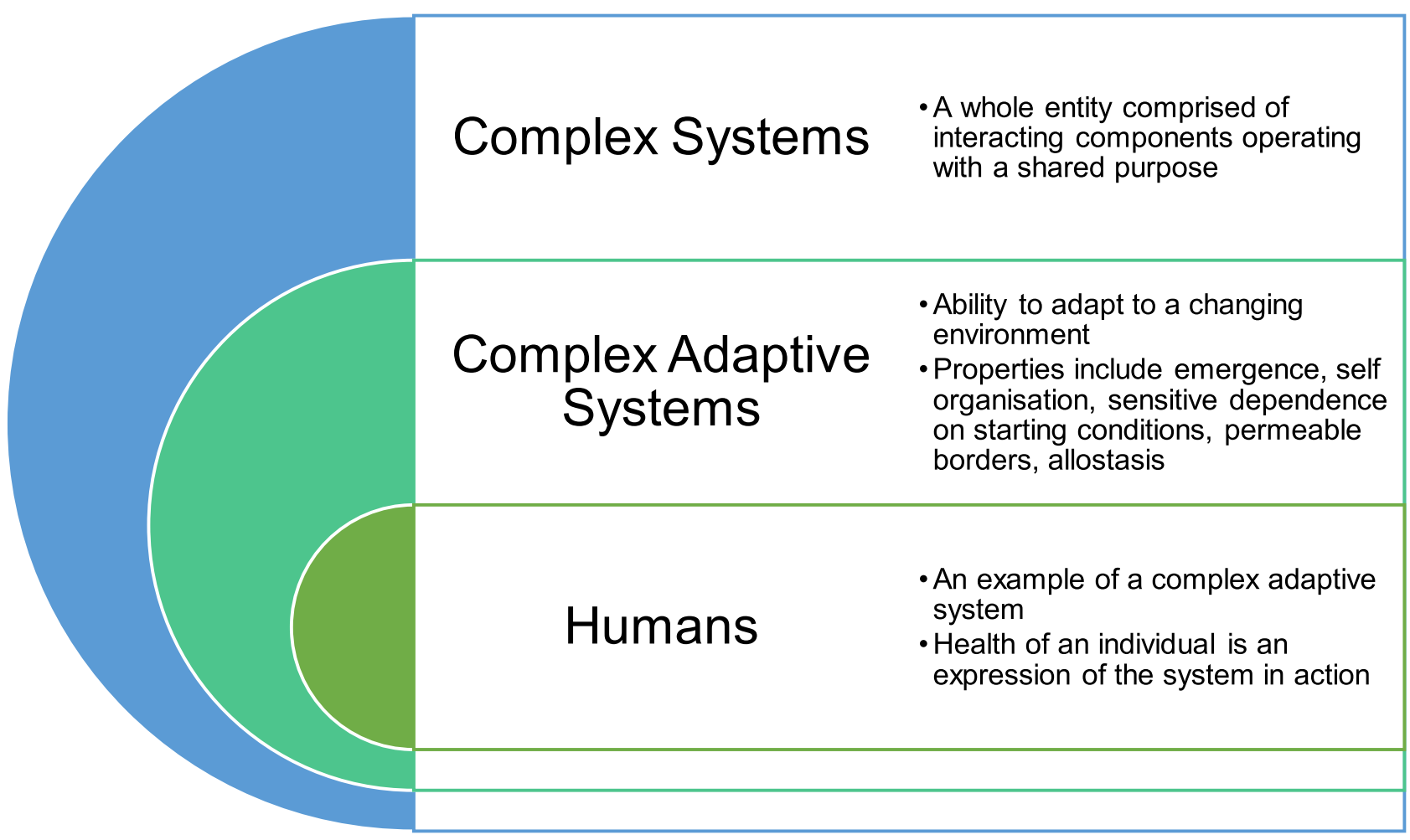

Figure I The relationship between complex systems, complex adaptive systems and the human organism.

where complexity principles have focused on health it has predominantly related to non-clinical applications, such as the social and organisational aspects of healthcare structures and networks, and health knowledge management, such as research networks, organisational affiliations, mentorship, peer support networks, and citation networks for example, ${ }^{26}$ genomic and proteomic interactions for example, ${ }^{27}$ and comorbidity and symptom relationships, identified using large datasets, for example. ${ }^{28}$ It has been noted that there is generally limited research, education, and implementation of complexity approaches within the health care domain. ${ }^{24,25}$ While the diagnosis of pathology using syndromic patterning reduces some of the complexity involved in clinical health care provision, it also reduces the capacity to individualise disease assessment and treatment, and to identify susceptibility and preclinical manifestations of disease. ${ }^{29,30}$ Movement towards a systems mindset is not a call for the abolition of reductionist methods and knowledge - understanding the parts is a valuable adjunct to working with the whole. ${ }^{31}$ Rather, the incorporation of systems thinking into biomedicine may offer new and novel opportunities to learn more about the nature of the human organism and enable the evolution of innovative approaches to improve the quality and safety of health care. ${ }^{12}$

While it is possible that clinicians from various professions engage in complexity thinking when managing cases, such as focusing on the relationships between the elements under consideration and looking beyond linear cause-and-effect links to seek emergent patterns, this does not appear to have been researched or documented within the literature, and there have been limited attempts to develop or codify formal frameworks in this area. While important work has been undertaken by the international community to raise the profile of a biopsychosocial perspective within health care, a notable example being the World Health Organisation's "International classification of functioning, disability and health", ${ }^{32}$ this has not effectively translated into an examination of clinical reasoning through a biopsychosocial lens or a complexity perspective. A research framework with a more encompassing reach than one that is designed to assess specific targeted interventions is necessary to evaluate the most effective way to manage the health of human organisms in all their complexity. In this paper, we forward the hypothesis that complexity science principles can be utilised in the examination of all aspects of clinical reasoning. 


\section{Complexity Science Tools for the Study of Health and Health Care}

While there is a justifiable theoretical basis for considering complexity science when researching health and health care, a clear understanding of practical tools useful to operationalise and apply a complexity science perspective in health research is still needed. Specific data visualisation tools (for example, mind maps and computergenerated network mappings) and analysis tools (for example, exploratory data analysis and computergenerated network analysis) may be appropriate for this purpose and are given consideration in this paper. Examples of various process steps to implement the use of the suggested tools are provided in Figure 2. The authors present these as possibilities; it is probable that a range of other options exist for future consideration. The potential of data visualisation is to reveal patterns and information not easily accessed by other means, enabling treatment development that is more considerate of the functioning of the entire human CAS organism, and leading to quality and safety improvements. The value of network analysis is to deepen the understanding of any system, which relative to human health may lead to novel insights regarding primary causality of disease, hypothetical risk states, leverage points and treatment targets.

\section{Mind Maps}

A network provides a graphical or conceptual representation of a complex system, ${ }^{25}$ and could be considered a complex system's skeleton. ${ }^{33}$ Mind maps offer an already accepted means of representing thought in a nonlinear and network structured format ${ }^{34}$ and represent a basic form of network mapping that may be amenable to advancing complexity science in health research. Mind maps consist of elements joined by links, which represent associative relationship, ${ }^{34,35}$ and encourage movement away from more traditional, natural, and innate "linear thought" towards radial identification of connections between elements. $^{34}$

\section{Mind Maps as a Knowledge Management Tool}

Mind mapping is a method for managing knowledge - by using a mind map knowledge can be organised, assessed, translated, and transferred - offering a means for overtly conceptualising the presenting state of a networked system. Mind maps have been used in a variety of disciplines (including economics, finance, marketing, public relations, and optometry) and the development of mind mapping software programs has increased the ease with which knowledge can be presented in this format. ${ }^{35}$ Mind maps are similar to concept maps, but differ in some key aspects, namely, mind maps are less structured, radial (rather than hierarchical), associative (rather than relational), ${ }^{35,36}$ and inclusive of any form of element rather than being limited to conceptual knowledge. Concept maps are increasingly used within educational settings to depict conceptually and structurally relational information; ${ }^{35-38}$ whereas mind maps are considered potentially more suited to note taking ${ }^{36}$ and brainstorming, ${ }^{35}$ and offer the capacity to associate disparate elements in an unstructured manner. Concept maps are information driven (for example, see Figure 3), whereas mind maps are representation focused (for example, see Figure 4). The value of a mind map is that it has the potential to provide a visual representation of how clinicians are making sense of the individual case presentation, in the context of the individual being a CAS. While mind maps are a potentially useful tool to assist clinicians in assessing patients' health needs, the focus of this paper is on their value as a tool for capturing clinical reasoning for research purposes.

\section{Mind Maps in Practice}

Mind maps have the qualities necessary to depict the inherent knowledge and case management intentions of the practitioner ${ }^{39}$ and may be generated during the case taking process or subsequently via a document review, and operational using one or a multitude of cases. A written or narrative account, often the format used in medical case management, lends itself more to a chronological or linearly organised portrayal of a case, whereas mind maps, with their radial network structure, provide an opportunity - using elements and connections - to map the case in the form of a system. The process of using a mind map often begins with the identification of a central element. In health care, the patient's presenting issue lends itself to this role. The next stage of this process is to begin linking aspects deemed relevant to the case to the determined starting point. These linked elements may comprise anything that is associated with the case and considered by the practitioner to bear influence on the presentation. Elements are linked in a radial networked structure, rather than a linear or hierarchical one, thereby creating a systems view of the case presentation. The clustering of elements into subsystems or types of influence may assist with 

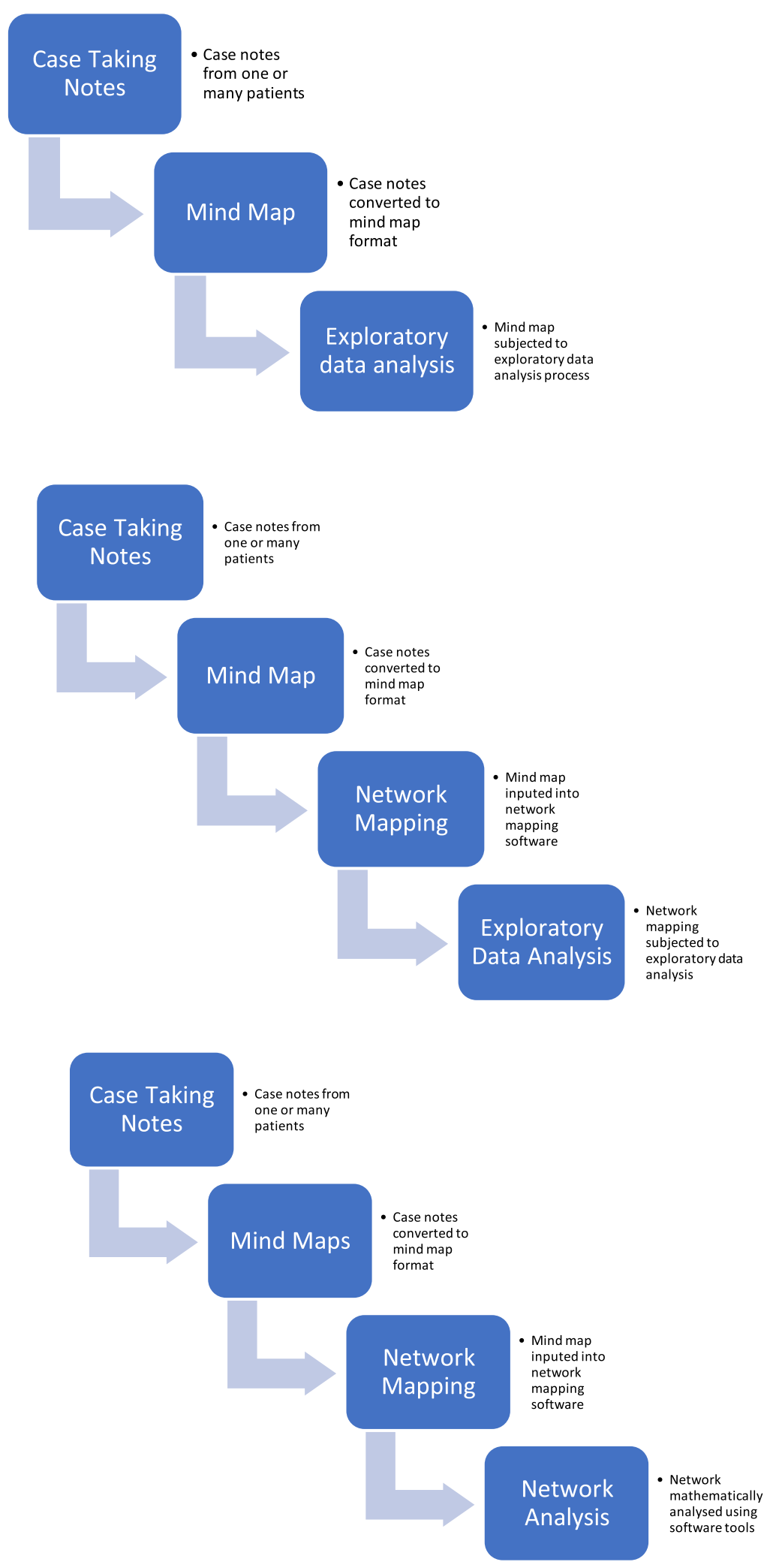

Figure 2 Three process options for use of systems tools to research primary health care provision and clinical reasoning.

identifying priority areas. Mind maps were primarily designed as a strategy to enhance learning, memory and critical thinking, and as an aid to organise thoughts. ${ }^{40}$
However, the characteristics of mind maps also means they are a potentially useful tool to represent the elements and associations found within a CAS, and to depict case 


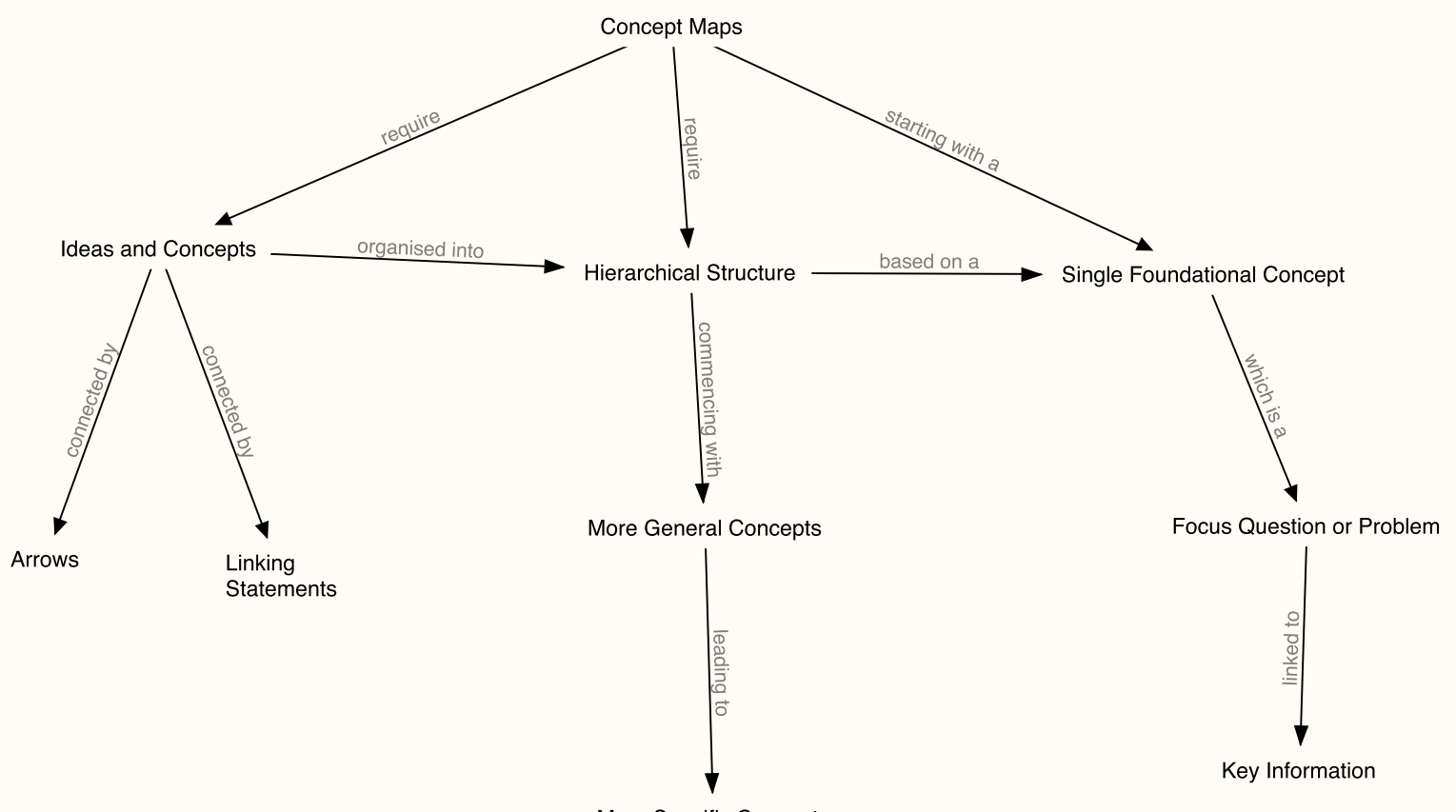

More Specific Concepts

Figure 3 Concept map example.

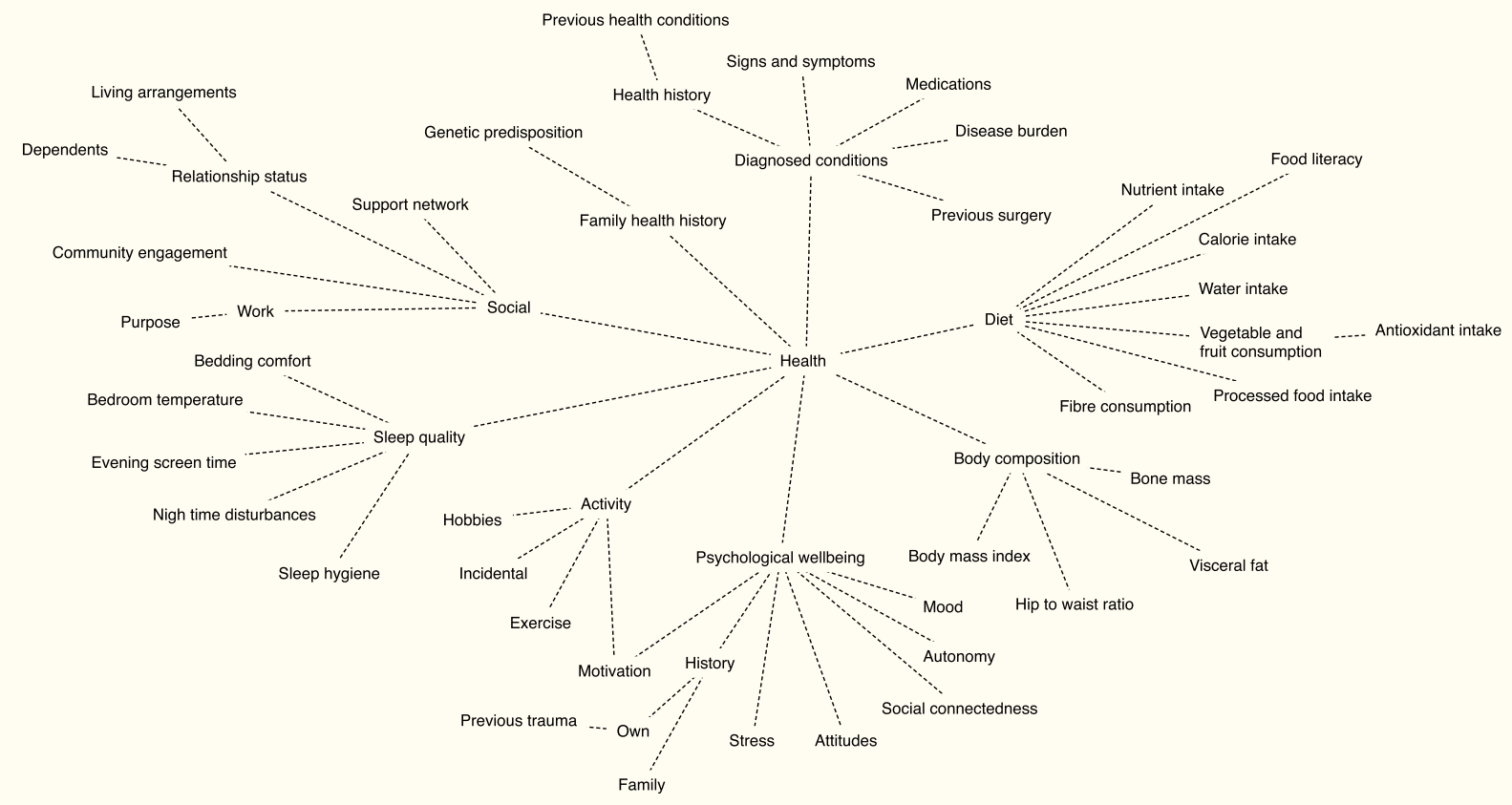

Figure 4 Mind map example. 
presentations as nonlinear network structures. As a tool, mind maps may be used to explore clinical understanding of a single case, or understanding across multiple similar cases, or the perspectives of more than one clinician. In a step beyond mind mapping, the dataset of elements and links derived from a patient's case (a mind map) may be inputted into a network mapping and analysis tool such as Gephi, ${ }^{41}$ allowing the data to be visualised, manipulated and analysed, ${ }^{42}$ either through exploratory data analysis or network analysis tools.

\section{Exploratory Data Analysis}

Within the context of complexity science, exploratory data analysis (EDA) provides an opportunity to explore and analyse a data set - such as a data set consisting of one or more mind maps - without preconceptions, in order to glean information about the phenomena under investigation. ${ }^{43}$ Instead of hypothesis testing and model building, EDA employs basic descriptive statistics and visualisation techniques to generate novel information based on the nature and potential causes of relationships amongst the data, which further leads to the development of testable hypotheses. ${ }^{43,44}$ This constitutes a method for patterned analysis of a dataset so that key features may be summarised. ${ }^{45}$ A primary method of applying EDA to graphical models (such as mind maps or network mappings) is to visualise $i t^{45}$ in an interactive and iterative manner, ${ }^{46}$ a useful tool for identifying structural features that may be elusive in other formats. ${ }^{47}$ Through network mapping, cumulative data representations may also be generated by inputting multiple mind maps (for example, of various patient presentations of a similar condition, or multiple mind maps of disparate conditions of a particular demographic). The goal of using EDA is to maximise what can be learned from the data, and this is achieved based on the principles of scepticism and openness: scepticism to ensure that any summarisation of the data does not misrepresent or obscure informative elements of the data, and the openness to be ready to receive unanticipated information and patterns. ${ }^{46}$ Rather than the more common confirmatory approach towards a dataset, EDA encourages an exploratory mindset, which allows the researcher to remain open to a wide range of possible alternatives. $^{46}$

\section{Network Analysis}

In addition to using EDA, network mapping representations may be explored using computer enabled network analyses including measurements of degree, distance, centrality, clustering and connectivity; all potentially providing information on the network structure and its functional properties, as well as clinical insights (see Table 1 for specific clinical examples). Degree is a measure of the number of connections that an element has, ${ }^{42}$ and indicates the extent to which an element is identified as being linked to other elements within a case presentation. Elements with high degree are known as hubs, ${ }^{48}$ and they act as key sites of influence within the network. The diameter of the structure is a measure of the shortest distance between the two most distal elements ${ }^{42}$ and is a measure of network connectedness, ${ }^{49}$ providing the parameters of the network. Centrality measures, including degree, closeness and betweenness, ${ }^{49}$ signify the importance of a node within a network ${ }^{47}$ and may assist with identifying treatment targets or leverage points. Betweenness centrality indicates the frequency at which an element appears on the shortest path between any pair of elements; ${ }^{42}$ an indication of the role different elements may perform in connecting and influencing other aspects of the network.

\section{Discussion}

Biomedicine has managed disease over the past 200 years or more by researching pathogenesis, inferring direct causal connections, and designing targeted interventions to disrupt those processes. ${ }^{23,50}$ This specific pathogenic approach has been extremely successful in treating acute disease and traumatic injury, has greatly expanded knowledge of physiology and pathophysiology, and advanced diagnostic and therapeutic effectiveness $^{13}$ but appears to have less adequately resolved contemporary health priorities, such as chronic and systemic disease which tend to be more complex and multifactorial. ${ }^{50} \mathrm{~A}$ direct, causal, and linear disease model and health care process is foundational to biomedicine: an agent causes disease, an identifiable set of symptoms emerge, and the disease is then resolved (or managed) with specific treatment. ${ }^{50}$ This paradigm has informed the bulk of current biomedical research and practice, ${ }^{50}$ in the past 50 years, treatment research has largely focused on the evaluation of specific interventions through the implementation of randomised controlled trials. ${ }^{51-53}$ Amongst biomedical researchers there is increasing awareness of the limits of biomedical reductionism to progress the scientific understanding of biology and disease. ${ }^{31,54}$ According to Pinsky, ${ }^{18}$ in order 
Table I Network Analysis Clinical Examples

\begin{tabular}{|c|c|c|}
\hline $\begin{array}{l}\text { Network } \\
\text { Analysis } \\
\text { Characteristic }\end{array}$ & Aspect of Clinical Case & Potential Insight Gained \\
\hline $\begin{array}{l}\text { Modularity or } \\
\text { community } \\
\text { identification }\end{array}$ & $\begin{array}{l}\text { A cluster of symptoms (for example: feeling cold, } \\
\text { weight gain, hair loss). }\end{array}$ & $\begin{array}{l}\text { Identification of an under functioning thyroid as a hypothetical risk, } \\
\text { prompting further investigation and possible early identification of } \\
\text { disease susceptibility and preventative intervention. }\end{array}$ \\
\hline Hub & $\begin{array}{l}\text { A highly connected element or hub (for example: } \\
\text { diet). }\end{array}$ & $\begin{array}{l}\text { Identification of diet as a keystone element and potential treatment } \\
\text { target within a specific case presentation, possibly enabling more } \\
\text { systemic and efficient treatment. }\end{array}$ \\
\hline Centrality & $\begin{array}{l}\text { An element with a high centrality measure (for } \\
\text { example: stress). }\end{array}$ & $\begin{array}{l}\text { Identification of stress as a potential leverage point due to it } \\
\text { impacting several other elements within the system (for example: } \\
\text { motivation, muscular tone, immune function, headaches, sleep quality, } \\
\text { social engagement), potentially redirecting and reducing overall } \\
\text { treatment needs, and enabling individualised treatment. }\end{array}$ \\
\hline Link direction & $\begin{array}{l}\text { Direction of interaction (for example: antibiotic use } \\
\text { in a directional link to urinary tract infection) }\end{array}$ & $\begin{array}{l}\text { Identification of causality or direction of influence amongst the } \\
\text { elements depicted in the mapping, prompting treatment of elements } \\
\text { further back in terms of origin, potentially allowing treatment to be } \\
\text { linked to source influences and causes rather than more indirect and } \\
\text { diffuse symptoms and issues. }\end{array}$ \\
\hline
\end{tabular}

to understand disease and its response to medical treatment, and to continue to improve the quality and safety of health care, we need to develop new tools and strategies that reflect complexity principles.

By exploring and understanding the interactions and organising principles that exist within a CAS, it is possible to gain deeper knowledge of the entire system than what would be possible from knowing the characteristics of the individual components alone. ${ }^{55}$ Knowledge comes not just from understanding the smallest possible components, it also comes from knowing how these components interact and this speaks to the tension between the reductionist (ie, the whole is the sum of its parts) and the holistic (ie, the whole is greater than the sum of its parts) stance. The complete, unified and complex human system in allostasis forms the basis of health, ${ }^{56}$ and reducing the system to its constituent parts negates the possibility of a comprehensive understanding of the whole system. ${ }^{57}$ While a complexity science perspective has been employed to explore CAS other than the human organism in various scientific domains to date, there has been limited engagement of complexity science principles within health care. It is possible that the provision of health care will be most effective in meeting the health needs of patients when it relates to the human organism as a CAS.

\section{Conclusions}

Clinical health care is frequently a complex endeavour. Complexity science is an emerging force within various scientific disciplines, but less so in medicine and primary health care. Complexity science, as a research framework, offers a means to move beyond the limits of reductionism and to further develop a comprehensive, systems-based understanding of the whole human organism. To develop this understanding, a change of perspective is needed towards probability, holism, and pattern recognition. Mind mapping is a method for managing knowledge and it offers a means for representing and assessing the presenting state of a complex adaptive system. Exploratory data analysis enables pattern recognition, leading to the development of testable hypotheses. A deeper level of understanding of the health of the human organism may be further achieved using network mapping and analysis software. The use of these tools and strategies, which are cognisant with complexity science, provides a means to broaden the paradigm of informing health care to one inclusive of complexity. Through the development of a complexity science framework to conceptualise and guide primary health care as well as research efforts, these areas will better align with the human organism as a complex adaptive system and will potentially lead to advancements in the efficiency, quality, and safety of health care. 


\section{Disclosure}

The authors report no conflicts of interest in this work.

\section{References}

1. Blalock JE, Smith EM. Conceptual development of the immune system as a sixth sense. Brain Behav Immun. 2007;21(1):23-33. doi:10.1016/j.bbi.2006.09.004

2. Foss L. Putting the mind back into the body a successor scientific medical model. Theor Med. 1994;15(3):291-313. doi:10.1007/ BF01313344

3. Kaplin A, Bartner S. Reciprocal communication between the nervous and immune systems: crosstalk, back-talk and motivational speeches. Int Rev Psychiatry. 2005;17(6):439-441. doi:10.1080/02646830500381419

4. Colloca L, Miller FG. Harnessing the placebo effect: the need for translational research. Philos Trans R Soc B Biol Sci. 2011;366 (1572):1922-1930. doi:10.1098/rstb.2010.0399

5. Dodd S, Dean OM, Vian J, Berk M. A review of the theoretical and biological understanding of the nocebo and placebo phenomena. Clin Ther. 2017;39(3):469-476. doi:10.1016/j.clinthera.2017.01.010

6. Thompson JJ, Ritenbaugh C, Nichter M. Reconsidering the placebo response from a broad anthropological perspective. Cult Med Psychiatry. 2009;33(1):112-152. doi:10.1007/s11013-008-9122-2

7. Chang-Claude J, Hermann S, Eilber U, Steindorf K. Lifestyle determinants and mortality in German vegetarians and health-conscious persons: results of a 21-year follow-up. Cancer Epidemiol Prev Biomark. 2005;14(4):963-968. doi:10.1158/1055-9965.EPI-04-0696

8. Willett WC, Koplan JP, Nugent R, Dusenbury C, Puska P, Gaziano TA. Prevention of chronic disease by means of diet and lifestyle changes. In: Jamison DT, Breman JG, Measham AR, et al. editors. Disease Control Priorities in Developing Countries. 2nd ed. World Bank; 2006. Available from: http://www.ncbi.nlm.nih.gov/ books/NBK11795/. Accessed October 30, 2020.

9. Eisenberger NI, Cole SW. Social neuroscience and health: neurophysiological mechanisms linking social ties with physical health. Nat Neurosci. 2012;15(5):669-674. doi:10.1038/nn.3086

10. Holt-Lunstad J. Why social relationships are important for physical health: a systems approach to understanding and modifying risk and protection. Annu Rev Psychol. 2018;69(1):437-458. doi:10.1146/ annurev-psych-122216-011902

11. Holt-Lunstad J, Birmingham WC, Light KC. Relationship quality and oxytocin: influence of stable and modifiable aspects of relationships. $J$ Soc Pers Relatsh. 2015;32(4):472-490. doi:10.1177/0265407514536294

12. Peters DH. The application of systems thinking in health: why use systems thinking? Health Res Policy Syst. 2014;12(1):51. doi:10. 1186/1478-4505-12-51

13. Sturmberg JP, Martin CM, Katerndahl DA. Systems and complexity thinking in the general practice literature: an integrative, historical narrative review. Ann Fam Med. 2014;12(1):66-74. doi:10.1370/ afm. 1593

14. Launer J. Complexity made simple. Postgrad Med J. 2018;94 (1116):611-612. doi:10.1136/postgradmedj-2018-136096

15. Lansing JS. Complex adaptive systems. Annu Rev Anthropol. 2003;32(1):183-204. doi:10.1146/annurev.anthro.32.061002.093440

16. Koithan M, Bell IR, Niemeyer K, Pincus D. A complex systems science perspective for whole systems of complementary and alternative medicine research. Forsch Komplementärmedizin Res Complement Med. 2012;19(s1):7-14. doi:10.1159/000335181

17. Ladyman J, Lambert J, Wiesner K. What is a complex system? Eur J Philos Sci. 2013;3(1):33-67. doi:10.1007/s13194-012-0056-8

18. Pinsky MR. Complexity modeling: identify instability early. Crit Care Med. 2010;38:S649-S655. doi:10.1097/CCM.0b013e3181f24484

19. Shoham J, Shoham A. The science of complex systems as a theoretical basis for complementary and integrative medical education. Explore. 2013;9(5):331-332. doi:10.1016/j.explore.2013.06.036
20. Holland JH. Studying complex adaptive systems. J Syst Sci Complex. 2006;19(1):1-8. doi:10.1007/s11424-006-0001-z

21. Mazzocchi F. Complexity and the reductionism-holism debate in systems biology: complexity and the reductionism-holism debate. Wiley Interdiscip Rev Syst Biol Med. 2012;4(5):413-427. doi:10. $1002 /$ wsbm. 1181

22. Wulff HR. The concept of disease: from Newton back to Aristotle. Lancet. 1999;354:SIV50. doi:10.1016/S0140-6736(99)90393-8

23. Mills PJ, Patel S, Barsotti T, Peterson CT, Chopra D. Advancing research on traditional whole systems medicine approaches. $J$ Evid Based Complement Altern Med. 2017;22(4):527-530. doi:10.1177/ 2156587217745408

24. Tuffin R. Implications of complexity theory for clinical practice and healthcare organization. BJA Educ. 2016;16(10):349-352. doi:10. 1093/bjaed/mkw013

25. Gustafsson M, Nestor CE, Zhang H, et al. Modules, networks and systems medicine for understanding disease and aiding diagnosis. Genome Med. 2014;6(10):82. doi:10.1186/s13073-014-0082-6

26. Onnela J-P, O'Malley AJ, Keating NL, Landon BE. Comparison of physician networks constructed from thresholded ties versus shared clinical episodes. Appl Netw Sci. 2018;3(1):28. doi:10.1007/s41109018-0084-1

27. Zhou Y, Hou Y, Shen J, et al. A network medicine approach to investigation and population-based validation of disease manifestations and drug repurposing for COVID-19. PLOS Biol. 2020;18(11): e3000970. doi:10.1371/journal.pbio.3000970

28. Milanlouei S, Menichetti G, Li Y, Loscalzo J, Willett WC, Barabási A-L. A systematic comprehensive longitudinal evaluation of dietary factors associated with acute myocardial infarction and fatal coronary heart disease. Nat Commun. 2020;11(1):6074. doi:10.1038/s41467-020-19888-2

29. Chan SY, Loscalzo J. The emerging paradigm of network medicine in the study of human disease. Circ Res. 2012;111(3):359-374. doi:10.1161/CIRCRESAHA.111.258541

30. Loscalzo J, Barabasi A-L. Systems biology and the future of medicine: systems biology and the future of medicine. Wiley Interdiscip Rev Syst Biol Med. 2011;3(6):619-627. doi:10.1002/wsbm.144

31. Greene JA, Loscalzo J, Malina D. Putting the patient back together Social medicine, network medicine, and the limits of reductionism. NEngl J Med. 2017;377(25):2493-2499. doi:10.1056/NEJMms1706744

32. World Health Organization, editor. International Classification of Functioning, Disability and Health: ICF. World Health Organization; 2001.

33. Barabasi. The architecture of complexity. IEEE Control Syst Mag. 2007;27(4):33-42. doi:10.1109/MCS.2007.384127.

34. Leeds AJ, Kudrowitz B, Kwon J. Mapping associations: exploring divergent thinking through mind mapping. Int $J$ Des Creat Innov. 2019;7(1-2):16-29. doi:10.1080/21650349.2018.1463178

35. Davies M. Concept mapping, mind mapping and argument mapping: what are the differences and do they matter? High Educ. 2011;62 (3):279-301. doi:10.1007/s10734-010-9387-6

36. Eppler MJ. A comparison between concept maps, mind maps, conceptual diagrams, and visual metaphors as complementary tools for knowledge construction and sharing. Inf Vis. 2006;5(3):202-210. doi:10.1057/palgrave.ivs.9500131

37. Daley BJ, Morgan S, Black SB. concept maps in nursing education: a historical literature review and research directions. J Nurs Educ. 2016;55(11):631-639. doi:10.3928/01484834-20161011-05

38. West DC, Park JK, Pomeroy JR, Sandoval J. Concept mapping assessment in medical education: a comparison of two scoring systems. Med Educ. 2002;36(9):820-826. doi:10.1046/j.1365-2923.2002.01292.x

39. Yu HW, Hussain M, Afzal M, et al. Use of mind maps and iterative decision trees to develop a guideline-based clinical decision support system for routine surgical practice: case study in thyroid nodules. J Am Med Inform Assoc. 2019;26(6):524-536. doi:10.1093/jamia/ ocz001 
40. Pudelko B, Young M, Vincent-Lamarre P, Charlin B. Mapping as a learning strategy in health professions education: a critical analysis. Med Educ. 2012;46(12):1215-1225. doi:10.1111/medu.12032

41. Bastian M, Heymann S, Jacomy M. Gephi: an open source software for exploring and manipulating networks. Proc Third Int ICWSM Conf. 2009;2. doi:10.13140/2.1.1341.1520

42. Yao N, Zhu X, Dow A, Mishra VK, Phillips A, Tu S-P. An exploratory study of networks constructed using access data from an electronic health record. J Interprof Care. 2018;32(6):666-673. doi:10. 1080/13561820.2018.1496902

43. Martinez WL, Martinez AR, Solka J. Exploratory Data Analysis with MATLAB. CRC Press LLC; 2017. Available from: http://ebookcentral. proquest.com/lib/uts/detail.action?docID=5475665. Accessed March 4, 2021.

44. Smith-Miles K. Exploratory data analysis. In: Lovric M editor. International Encyclopedia of Statistical Science. Springer; 2011:486-488. doi:10.1007/978-3-642-04898-2_242

45. Datar R, Garg H. Hands-On Exploratory Data Analysis with R: Become an Expert in Exploratory Data Analysis Using $R$ Packages. 1st ed. Packt Publishing, Limited; 2019.

46. Hartwig F, Dearling BE. The exploratory perspective. In: Exploratory Data Analysis. SAGE Publications Inc.; 1979. doi:10.4135/97814 12984232

47. Newman M. Networks: An Introduction. Oxford University Press; 2018.

48. Mitchell M. Complexity; a Guided Tour. Oxford University Press; 2009.
49. McCulloh I, Armstrong H, Johnson A. Social Network Analysis with Applications. John Wiley \& Sons, Incorporated; 2013. Available from: http://ebookcentral.proquest.com/lib/uts/detail.action?docID= 1211931. Accessed March 17, 2021.

50. Jonas WB, Beckner W, Coulter I. Proposal for an integrated evaluation model for the study of whole systems health care in cancer. Integr Cancer Ther. 2006;5(4):315-319. doi:10.1177/1534735406295565

51. Hyland ME. Using the placebo response in clinical practice. Clin Med. 2003;3(4):347-350. doi:10.7861/clinmedicine.3-4-347

52. Kaptchuk TJ. The placebo effect in alternative medicine: can the performance of a healing ritual have clinical significance? Ann Intern Med. 2002;136(11):817-825. doi:10.7326/0003-4819-136-11200206040-00011

53. Wampold BE, Imel ZE, Minami T. The story of placebo effects in medicine: evidence in context. J Clin Psychol. 2007;63(4):379-390. doi:10.1002/jclp.20354

54. Plsek PE, Greenhalgh T. Complexity science: the challenge of complexity in health care. BMJ. 2001;323(7313):625-628. doi:10.1136/ bmj.323.7313.625

55. Barabasi A-L. Network Science; 2016. Available from: http://net worksciencebook.com/. Accessed March 20, 2020.

56. Connolly G. Naturopathic case taking. In: Sarris J, Wardle J, editors. Clinical Naturopathy: An Evidence-Based Guide to Practice. 2nd ed. Churchill Livingstone Elsevier; 2014:1-18.

57. Power J. Reductionism and nursing clinical reality. Biomed J Sci Tech Res. 2017;1(3):720-721 doi:10.26717/BJSTR.2017.01.000285
Journal of Multidisciplinary Healthcare

\section{Publish your work in this journal}

The Journal of Multidisciplinary Healthcare is an international, peerreviewed open-access journal that aims to represent and publish research in healthcare areas delivered by practitioners of different disciplines. This includes studies and reviews conducted by multidisciplinary teams as well as research which evaluates the results or conduct of such teams or healthcare processes in general. The journal covers a very wide range of areas and welcomes submissions from practitioners at all levels, from all over the world. The manuscript management system is completely online and includes a very quick and fair peer-review system. Visit http://www.dovepress.com/testimonials. php to read real quotes from published authors. 